Arhe XVII, 34/2020

UDK 179:616-036.86

DOI https://doi.org/10.19090/arhe.2020.34.275-293

Originalni naučni rad

Original Scientific Article

\author{
ANĐELA H. KAUR ${ }^{1}$ \\ Univerzitet Severne Dakote, Grand Forks, Severna Dakota, SAD
}

\title{
BIOETIČKA ANALIZA UTICAJA RUTINIZACIJE GENETIČKOG ISPITIVANJA NA POJAM INVALIDNOSTI
}

Sažetak: Tehnološki napredak u biomedicini uvodi nova etička pitanja $u$ medicinsku praksu. Pronalazak neinvazivnog genetičkog ispitivanja je primer koji zahteva proširivanje problematizacije dostignuća biomedicinske nauke. Nakon komercijalizacije neinvazivnog genetičkog ispitivanja u SAD i na globalnom nivou, genetičko ispitivanje se sve više popularizuje kao neophodan deo primarne medicinske prakse i rutinske zdravstvene zaštite. U ovom radu se zastupa stav da rutinizacija genetičkih ispitivanja povećava diskriminaciju u pogledu invalidnosti u profesionalnoj medicinskoj praksi i normalizuje predrasude o invalidnosti u društvu.

Ključne reči: bioetika invalidnosti, genetička ispitivanja, rutinizacija medicinskih mera, pristanak obaveštenog pacijenta, emotivna povređenost, epistemička nepravda, društvena i zakonska diskriminacija

Usled stalnog razvoja biomedicinskih tehnologija, genetička ispitivanja su postala lakše dostupna široj populaciji. U današnje vreme ljudi mogu da se podvrgnu genetičkom ispitivanju iz različitih razloga i u različitim fazama svog života. Shodno tome, genetička ispitivanja postaju ustaljeni deo medicinske prakse. Lekari i medicinski stručnjaci širom sveta rutinski preporučuju pacijentima da se podvrgnu genetičkom ispitivanju. $U$ ovom radu razmatraju se etički problemi kao posledica

\footnotetext{
${ }^{1}$ E-mail adresa autorke: andjela.kaur@und.edu
} 
takve rutinizacije, iz perspektive bioetike invalidnosti u Sjedinjenim Američkim Državama.

Genetički testovi koji se nude pacijentima u Sjedinjenim Američkim Državama mogu se podeliti u tri kategorije: prediktivni testovi, testovi za otkrivanje genetske predispozicije za bolesti i dijagnostički testovi. Prve dve vrste testova su često povezane sa planiranjem porodice, dok se treća navedena kategorija može koristiti u svrhu planiranja porodice, ali i u svrhu postavljanja dijagnoze u bilo kojoj fazi života. Testovi nosilaca mutacije koriste se da bi se utvrdilo da li osoba poseduje genetsku mutaciju koja će verovatno postati simptomatska tokom njenog života ili koja može, pod određenim okolnostima, prouzrokovati genetski poremećaj kod potomostva. Tokom trudnoće sprovode se prediktivna genetička ispitivanja, koja se takođe nazivaju prenatalna genetička ispitivanja, kako bi se utvrdilo prisustvo genetske anomalije kod fetusa. Dijagnostičko ispitivanje se koristi za identifikovanje genetskog poremećaja kod fetusa, deteta ili odrasle osobe.

Bez obzira na vrstu testa koji koristi ili genetsko stanje koje testira, sama praksa genetičkog ispitivanja je relevantna za bioetiku invalidnosti. Neka od pitanja koja se postavljaju u ovom kontekstu su: Da li lekari treba rutinski da preporučuju genetičko ispitivanje?; Da li medicinsko osoblje treba da preporučuje selektivne abortuse $\mathrm{u}$ slučajevima utvrđene mutacije kod fetusa?; Koja obaveštenja je neophodno dati pacijentu kako bi mogao da donese samostalnu i obaveštenu odluku o pristanku na različite vrste genetičkog ispitivanja? Da li je pacijentima potrebno pružiti nemedicinske informacije o socijalnim, psihološkim i kulturnim iskustvima osoba sa invalidnosti? U nameri da odgovore na ovakva pitanja, bioetičari koji se bave invalidnošću uglavnom navode argumente koji se mogu podvesti pod dve centralne teme: rutinizacija genetičkog ispitivanja i ,pristanak obaveštenog pacijenta" (eng. informed consent).

\section{RUTINIZACIJA}

Rutinizacija medicinskih intervencija je uobičajena u zdravstvu. Primarne medicinske intervencije mogu biti propisane zakonima o 
zdravstvu (npr. određene vakcinacije su obavezne za sve građane) ili se mogu pacijentima rutinski preporučivati od strane lekara i kada nisu zakonski propisane. Shodno tome, termin „rutinizacija“ genetičkog ispitivanja odnosi se na promociju genetičkog ispitivanja kao komponente primarne medicinske prakse. Rutinizacija može imati sledeće oblike: a) podjednako preporučivanje testova za otkrivanje predispozicije i pacijentima koji imaju i pacijentima koji nemaju porodični rizik od genetskih poremećaja; b) preporučivanje prediktivnih testova trudnicama kao da su oni deo primarne ginekološke prakse; c) preporučivanje dijagnostičkog genetičkog ispitivanja kao neophodnog sledećeg koraka u slučaju pozitivnog prediktivnog testa; $i \mathrm{~d}$ ) upotrebljavanje jezika koji signalizira pacijentu i široj javnosti da je genetičko testiranje opšteprihvaćena mera zdravstene zaštite. Pored ovih vrsta promocije genetičkog ispitivanja, rutinizacija takođe uključuje mere koje otvoreno zabranjuju ili prikriveno sugeriraju pacijentima da odbijaju genetičko ispitivanje. Ove mere mogu uključivati kazne za odbijanje zakonski propisanih ispitivanja, izbegavanje razgovora o rizicima vezanih za genetičko ispitivanje i ograničenost rezultata ovih dijagnostičkih i prediktivnih mera, kao i nedostupnost informacije o pravu pacijenata da odbiju medicinsku intervenciju. ${ }^{2}$

Rutinizaciji genetičkog ispitivanja takođe mogu doprineti faktori izvan politike javnog zdravlja i upravljanja zdravstvenom zaštitom. S obzirom da proizvođači genetičkih testova imaju neposredni interes za prodaju svojih proizvoda, promocija genetičkog ispitivanja takođe je povezana sa finansijskim ciljevima biomedicinske industrije. Pre pronalaska neinvazivnog prenatalnog testiranja (eng. Non-Invasive Prenatal Testing, NIPT), komercijalni proizvođači genetičkih testova uglavnom su delovali u tesnoj saradnji sa davaocima medicinskh usluga i u skladu sa zakonima. Pod ovim uslovima, genetičko ispitivanje se smatralo invazivnim postupkom, a genetičke analize su se rutinski preporučivale samo osobama sa rizikom, poznatim nosiocima mutacija i ženama za koje se smatra da imaju medicinski opravdan rizik od

\footnotetext{
${ }^{2}$ Suter, S. (2002). Routinization of Prenatal Testing. American Journal of Law and Medicine 28, str. 245.
} 
hromozomske anomalije. ${ }^{3}$ Međutim, otkako je 2011. godine zbog napretka tehnologije omogućena proizvodnja neinvazivnog genetičkog ispitivanja za masovnu primenu, otpočela je mnogo agresivnija prodaja čitavog niza neinvazivnih testova za otkrivanje raznih genetskih poremećaja. U periodu između 2011. i 2019. godine, broj kompanija koje plasiraju neinvazivne testove u SAD porastao je sa četiri na četrdeset, dok projekcije na globalnom nivou pokazuju da će industrija genetičkih ispitivanja do 2025. godine ostvariti prihod od preko 2,5 milijardi USD. ${ }^{4}$ Upečatljivo je to što ove firme prodaju testove svim zainteresovanim, bez obzira na njihovu istoriju bolesti i faktore rizika povezane sa hromozomskim abnormalnostima. Važno je napomenuti da se neinvazivno genetičko ispitivanje u SAD koristi za otrkrivanje predispozicije za određene bolesti, nakon čega se, u slučaju otkrivanja predispozicije, pacijentu preporučuje dijagnostičko testiranje.

Zbog komercijalizacije neinvazivnog genetičkog ispitivanja i ubrzane rutinizacije genetičkih ispitivanja, bioetičari iz oblasti javnog zdravlja se po prvi put suočavaju sa pitanjima kao što su: Da li testiranje treba da bude dostupno svim zainteresovanim građanima?; Da li zdravstveno osiguranje treba da plaća za usluge genetičkog testiranja?; Da li prodaja testova treba da bude regulisana zakonima o zdravstvenoj zaštiti i propisima u oblasti javnog zdravlja?; Da li treba ograničiti proizvodnju genetičkih testova i upotrebu genetičkog ispitivanja? U SAD-u se dodatno postavljaju pitanja o vrednosti ove intelektualne svojine, budući da se broj kompanija koje proizvode testove stalno povećava, a time i broj sudskih sporova u oblasti patenata i intelektualne svojine. $^{5}$

\footnotetext{
${ }^{3}$ Invazivni testovi su uključivali amniocentezu i kordocentezu; obe ove mere mogu izazvati pobačaj.

4 National Council on Disability (2019). Genetic testing and the rush to perfection (Bioethics and Disability Series). National Council on Disability, str. 67.

5 Agarwal, A., Sayres, L. C., Cho, M. K., Cook-Deegan, R., \& Chandrasekharan, S. (2013). Commercial landscape of noninvasive prenatal testing in the United States. Prenatal diagnosis, 33 (6), str. 524.
} 


\section{PRISTANAK OBAVEŠTENOG PACIJENTA}

U Sjedinjenim Američkim Državama izraz ,pristanak obaveštenog pacijenta“" odnosi se kako na čin kojim se pacijent saglašava sa određenom medicinskom intervencijom, tako i na razgovor lekara i pacijenta koji prethodi takvoj saglasnosti. Pristanak obaveštenog pacijenta za premisu uzima uverenje da pacijenti imaju pravo da odlučuju kojim medicinskim merama će se podvrći. Stoga je i etička i zakonska obaveza lekara u SAD da pribave saglasnost pacijenta pre nego što započnu medicinske intervencije u situacijama koje ne zahtevaju urgentno reagovanje. Drugim rečima, s obzirom da pacijenti imaju pravo na obaveštenje, pružalac medicinske zaštite ima obavezu da takvo obaveštenje obezbedi.

Brojni zakoni o zdravstvenoj zaštiti i javnom zdravlju, medicinske ustanove, medicinski stručnjaci, studije o invalidnosti, kao i svedočenja članova pokreta invalidnosti bave se preporukama o sadržaju i načinu prikupljanja obaveštenja koje je potrebno dostaviti pacijentu prilikom donošenja odluke o ponuđenim medicinskim merama. Imajući u vidu širok spektar preporučenih mera, bioetičari invalidnosti se slažu da: a) donosilac odluke treba da bude osoba sposobna da odluku donese samostalno ili putem procesa donošenja odluke uz podršku ${ }^{6}$; b) odluku treba donositi slobodno, bez nagovaranja ili prinude; c) osoba koja donosi odluku treba potvrdi usmeno ili putem alternativnih sredstava komunikacije da je razumela obaveštenje koje joj je saopšteno; i d) medicinsko osoblje treba da pruži dovoljno informacija pacijentu da bi on mogao da napravi obavešteni izbor.

Sledeća tri standarda, izražena kao smernice u formi pitanja, mogu se koristiti za procenu adekvatnosti informacija koje se razmenjuju

\footnotetext{
${ }^{6}$ Ovde se ima na umu donošenje odluke uz podršku (eng. Supported DecisionMaking) koje omogućava osobama koje nemaju zakonsko pravo da donese odluke po osnovi sudske i medicinske procene da ne poseduju sposobnost da razumeju prirodu, značaj ili domašaj predloženog ispitivanja, da donose odluke o svom životu. Shodno tome, u SAD se tim osobama može dozvoliti da uz podršku njihovog pravnog zastupnika donose odluke o podvrgavanju medicinskim merama.
} 
u procesu pristanka obaveštenog pacijenta: a) Subjektivni standard: Šta ovaj pacijent treba da zna i razume da bi doneo odluku na osnovu informacija?; b) Standard razumnog pacijenta: Šta prosečan pacijent treba da zna da bi mogao da da obeavešteni pristanak?; i c) Standard razumnog lekara: Šta bi tipični lekar rekao o ovom postupku? Iako sudovi preferiraju upotrebu drugog standarda, davaoci usluga su oni koji imaju obavezu da utvrde koji standard je najadekvatniji u datoj situaciji. ${ }^{7}$

Nadalje, u SAD pravna doktrina o pristanku obaveštenog pacijenta nalaže lekarima da obaveste pacijenta o sledećem: a) dijagnozi; b) prirodi predložene medicinske intervencije; c) očekivanom ishodu; d) ozbiljnom mogućem riziku i komplikacijama po zdravlje, kao i koristima od predložene intervencije; e) rizicima i koristima od alternativnih tretmana; f) rizicima i koristima povezanim sa odbijanjem intervencije; g) mogućim poznatim efektima intervencije na pojedinačnog određenog pacijenta (personalizovane informacije); i h) ličnim ili ekonomskim interesima lekara koji mogu uticati na njegove preporuke, ako postoje. ${ }^{8}$

U kontekstu zdravstvenih sistema, obrasci za pristanak obaveštenog pacijenta služe kao dokumentacija kojom se dokazuje poštovanje zakonskih propisa. Međutim, u svakodnevnoj praksi i uslovima užurbanog radnog okruženja, često se događa da složeni proces donošenja odluke na osnovu dobijenih informacija bude sveden samo na čin pukog parafiranja obrasca o pristanku obaveštenog pacijenta. ${ }^{9}$

Ukratko, rutinizacija genetičkih ispitivanja je komplikovan i višeslojan proces koji se zasniva na prioritetima naučnih i tehnoloških inovacija. S obzirom da se ubrzani tehnološki razvoj, politika javnog zdravlja i komercijalni interesi prepliću, etičari iz različitih disciplina

\footnotetext{
${ }^{7}$ Hall, D. E., Prochazka, A. V., \& Fink, A. S. (2012). Informed consent for clinical treatment. CMAJ: Canadian Medical Association journal = Journal de l'Association medicale canadienne, 184(5), str. 535.

${ }^{8}$ Murray, B. (2012). Informed consent: what must a physician disclose to a patient. Virtual Mentor 14 (7), str. 563 - 566. AMA Journal of Ethics. https://journalofethics.ama-assn.org/article/informed-consent-what-mustphysician-disclose-patient/2012-07

${ }^{9}$ Hall, D. E., Prochazka, A. V., \& Fink, A. S. (2012). Informed consent for clinical treatment. CMAJ: Canadian Medical Association journal = Journal de l'Association medicale canadienne, 184(5), str. 538.
} 
postavljaju pitanja o rutinizaciji kao sredstvu za popularisanje naučnih i tehnoloških dostignuća. Pristanak obaveštenog pacijenta je postupak kojim se pacijent saglašava da se podvrgne medicinskoj meri koju mu je lekar predložio. Ovaj proces se oslanja na kompleksna etička razmatranja i pravne akte. Bioetičari i donosioci zakona o zdravstvenoj zaštiti i pravima pacijenata slažu se da je razmena informacija ključna za procedure davanja pristanka obaveštenog pacijenta, ali nije dovoljno jasno koje informacije treba uključiti u tu proceduru.

Bioetika invalidnosti pokazuje kako rutinizacija i pristanak obaveštenog pacijenta utiču na život osoba koje žive sa invaliditetom i kako dostupnost medicinskih mera utiče na konceptualizaciju invalidnosti u medicini i zdravstvenoj zaštiti. Takva poimanja invalidnosti stvorena u oblastima medicine, javnog zdravlja i zakonodavstva često utiču na javno mnjenje o invalidnosti. Štaviše, poimanje invalidnosti koje se oslanja na ove epistemološke izvore, direktno utiče na definicije invalidnosti u društvu.

Analize ovih procesa koje su sproveli bioetičari invalidnosti izražavaju multidisciplinarni karakter bioetike invalidnosti i složenost koja je svojstvena pojmu invalidnosti. ${ }^{10}$ Pitanja koja oni postavljaju zasnivaju se na njihovim ličnim iskustvima, istraživanjima u oblasti društvenih nauka, pravničkom znanju i radu istoričara invalidnosti, umetnika i filozofa. Takođe, bioetika invaliditeta se, kao humanistička disciplina, oslanja na znanje i delatnost zagovornika prava i jednakosti invalida $^{11}$. U SAD od 1970-tih godina postoji organizovani pokret

${ }^{10}$ Ouellette, A. (2011). Bioethics and disability: Toward a disability-conscious bioethics (Cambridge Disability Law and Policy Series). Cambridge: Cambridge University Press, str. 67.;

Scully, J. (2008). Disability bioethics: Moral bodies, moral difference. Lantham: Rowman\&Littlefield Publishers, Inc., str. 134; Amundson, T. (2008). Bioethics and Disability Rights: Conflicting Values and Perspectives. Journal of Bioethical Inquiry, 5(2), str. 114.

${ }^{11}$ U ovom radu se koriste izrazi „osoba sa invalidnošću“ i ,invalidi“ da bi se napravila razlika između pojedinaca (osoba sa invalidnošću) i manjinske grupe (invalida). Prvi izraz je u skladu sa trenutnom praksom političke korektnosti u vezi sa invalidnošću, a drugi ukazuje na stav kritičkih studija invalidnosti i progresivnih članova pokreta invalidnosti da termin ,invalidi““ treba usvojiti kao 
invalidnosti u okviru kojeg se pitanja iz bioetike invalidnosti preispituju sa stanovišta osoba s invaliditetom, dakle sa stanovišta onih koji su lično iskusili posledice biomedicinskih dostignuća i medicinske prakse. Etički problemi koji se javljaju prilikom razmatranja svih ovih perspektiva, na razmeđi invalidnosti i rutinizacije i pristanka obaveštenog pacijenta $u$ genetičkom ispitivanju, mogu se grupisati u tri opšte kategorije: a) emotivna povređenost b) epistemička nepravda i c) socijalna i zakonska diskriminacija.

\section{EMOTIVNA POVREĐENOST}

Emotivna povreda nastaje kada se pacijentu pruži znanje o problemu u vezi sa njegovim zdravljem za koji se pretpostavlja da ne postoji rešenje. Shodno tome, emotivno povređivanje je imanentno prediktivnom testiranju bilo trudnica ili potencijalnih nosilaca. Na primer, kada nosilac sazna da ima velike šanse da se razboli od neizlečive bolesti, on biva izložen saznanju o svojoj budućnosti koju ne može promeniti. Kada se ispitivanje nosilaca rutinizira, rizik od emotivnog povređivanja velikog broja pacijenata se povećava. Studija sprovedena na uzorku od preko stotinu žena koje su podvrgnute neinvazivnom genetičkom ispitivanju (korišćeni su samo uzorci krvi) je pokazala da se kod svih njih javila anksioznost $\mathrm{u}$ vezi sa ispitivanjem. ${ }^{12}$ Iako takva rutinska ispitivanja mogu naneti emotivnu povredu većem broju ljudi zbirno posmatrano, ovakva povećana izloženost riziku može se opravdati poštovanjem individualnog prava svakog pacijenta da samostalno donosi odluke o podvrgavanju medicinskim merama, kao i pravu da bira da li želi da bude obavešten o nalazu ispitivanja.

odrednicu pripadnosti manjinskoj grupi čiji su članovi pojedinačno i kolektivno izloženi diskriminaciji. Budući da ljudsko iskustvo nije moguće dosledno podeliti na lično i kolektivno jer su u pitanju međuzavisna iskustva, definicije ovih izraza se često prepliću u literaturi i u ovom radu.

${ }^{12}$ Farrell, R., Agatisa, P., Mercer, M., Mitchum, A., \& Coleridge, M. (2016). Expanded indications for noninvasive prenatal genetic testing: Implications for the individual and the public. Ethics, Medicine, and Public Health, 2(3), 383391. https://doi.org/10.1016/j.jemep.2016.05.002, 
Da bi uvažio autonomiju pacijenta, lekar ili ovlašćeni medicinski radnik treba da razgovara sa pacijentom o emotivnom povređivanju koje bi mogla da izazove saznanje o njegovoj budućnosti ili predviđanje njegovog zdravstenog stanja. Davaoci medicinskih usluga često zanemaruju potrebu da se razgovara o emotivnom povređivanju prilikom pribavljanja pristanka obaveštenog pacijenta na genetičko ispitivanje. ${ }^{13}$ Pa čak i kada se takav razgovor dogodi, medicinari redovno pogrešno predstavljaju emotivno povređivanje prouzrokovano novim saznanjem kao bolju alternativu u odnosu na problem koji predstavlja neotkrivena invalidnost za koju se pretpostavlja da je sama po sebi tragedija. Drugim rečima, umesto da razgovaraju o razlozima zbog kojih bi neko mogao da se dvoumi da li treba da rizikuje saznanje o vlastitoj budućnosti, davaoci usluga stavljaju potencijalnu opasnost od invalidnosti u prvi plan kao primarnu emotivnu povredu koju izaziva genetičko ispitivanje. ${ }^{14}$ Takvo pogrešno predstavljanje ove etičke dileme pojačava strah i strepnju pacijenta za sopstvenu budućnost jer se njihova želja da saznaju svoj broj hromozoma uzima kao želja da saznaju svoju tragičnu sudbinu. Istovremeno, invalidnost se pacijentu predstavlja kao po definiciji tragičan, jedinstveni negativan ishod njegovog reproduktivnog potencijala, ne uzimajući u obzir činjenicu da se tragedije dešavaju iz različitih razloga i u bilo kom trenutku života ljudi i bez obzira na njihov genetički sklop. $^{15}$

Što je najvažnije, invalidnost $u$ ovim razgovorima između pacijenata i davaoca medicinske usluge figurira samo kao ekvivalent negativnog ličnog iskustva $i$, šire posmatrano, kao oblik ljudskog postojanja koji zaslužuje sistematsko iskorenjivanje. Takvo poimanje invalidnosti kao tragedije u suprotnosti je sa iskustvima osoba sa invaliditetom koje neprestano izjavljuju da su zadovoljne svojim životima, da njihovi životi imaju smisla i da invalidnost ne umanjuje

${ }^{13}$ Suter, S. (2002). Routinization of Prenatal Testing. American Journal of Law and Medicine 28, str. 260.

${ }^{14}$ Suter, S. (2002). Routinization of Prenatal Testing. American Journal of Law and Medicine 28, str. 269.

${ }^{15}$ Andrews, L.B. (1996). Prenatal Screening and the Culture of Motherhood. Hastings L. J., 47, str. 970. 
vrednost njihovog života. ${ }^{16} \mathrm{~S}$ druge strane, takvo iznošenje predrasude da invalidnost treba iskoreniti zanemaruje činjenicu da prekid trudnoće, sam po sebi, ne eliminiše opšte prisustvo invalidnosti u svetu. Shodno tome, bioetičari invalidnosti preporučuju da se rasprave o pristanku obaveštenog pacijenta usredsrede na predmetno pitanje, naime, na rizike $\mathrm{i}$ koristi od saznanja šta budućnost može da donese dotičnoj osobi u njenim konkretnim životnim okolnostima. Ovi razgovori bi tada trebalo da uključuju tačne informacije o iskustvima osoba koje žive sa određenom bolešću koja je otkrivena ili potvrđena testom, a treba da ih pružaju osobe koje imaju životno iskustvo te određene bolesti, kao i življenja sa invalidnosti uopšteno. Dakle, stavovi invalida ili osoba koje vode brigu o njima bi trebalo da budu uključeni u razgovore o pristanku pacijenta da se podvrgne genetičkom ispitivanju.

Važno je imati na umu da emotivno povređivanje prouzrokovano rutinizacijom i manjkavim postupkom pribavljanja saglasnosti pacijenta utiče na invalide kao manjinsku grupu. Pripadnici pokreta invalidnosti u SAD često koriste takozvani „ekspresionistički argument“ da pokažu da rutinizacija prenatalnog ispitivanja povređuje osobe sa invalidnosti. Prema ovom argumentu rutinizacija genetičkog ispitivanja šalje jasnu i glasnu poruku potencijalnim roditeljima i javnosti da je bolje da se opredele da eliminišu genetske markere invalidnosti, što zauzvrat povređuje ljude koji već žive s tim istim markerima. ${ }^{17}$

\section{EPISTEMIČKA NEPRAVDA}

Epistemička nepravda je diskriminatorna praksa kojom se određeni pojedinac ili grupe ljudi isključuju iz procesa kreiranja i

16 Asch, A. (2001). Disability, bioethics and human rights in Albrecht, G., Seelman, K., \& Bury, M. (2001). Handbook of disability studies. Sage Publications, str. 313.; Longmore, P. K., (1995) Medical decision making and people with disabilities: A clash of cultures. Journal of Law and Medical \& Ethics 23 (1), str. 84.

${ }^{17}$ Parens, E. and Asch, A. (2003), Disability rights critique of prenatal genetic testing: Reflections and recommendations. Ment. Retard. Dev. Disabil. Res. Rev., 9, str. 22. 
prenošenja znanja usled predrasuda na osnovu njihovog identiteta. $U$ kontekstu rutinizacije i pristanka obaveštenog pacijenta, epistemička nepravda se javlja u svim situacijama u kojima je prisutna (pogrešna) pretpostavka da će pacijenti bezuslovno pristati, i da treba da pristanu, na testove koje je kreirala biomedicina i koje su preporučili njihovi lekari. Ovo je neizrečeno očekivanje medicinskog osoblja kao i pacijenata, a institucionalizovano je kroz zakonske odredbe, bolničke pravilnike o radu, promotivne materijale o genetičkom ispitivanju i, generalno, putem reklamiranja genetičkog ispitivanja kao rutinske medicinske prakse. Zbog takvog nekritičkog promovisanja stavova o zdravlju i dobrobiti kojim se prioritetizuju biomedicinske nauke kao autoritativni model znanja, pacijenti su prinuđeni da prihvate ovu epistemičku perspektivu kao jedino, a samim tim i ,istinsko“ znanje. Ovaj epistemički vakuum nanosi štetu pacijentima jer ograničava njihovu bazu znanja i uvodi pretpostavku da je pacijent ,neznalica”. Onog trenutka kada se prihvati pretpostavka da nemaju mogućnost da spoznaju, pacijentima se više ne daju sve informacije koje su im potrebne da bi razumeli obaveštanje o medicinskoj meri na koju treba da pristanu, i na taj način oni bivaju podvrgnuti rutini koju ne mogu promeniti i na koju ne mogu davati primedbe.

Epistemička nepravda takođe označava sistematsko omalovažavanje informacija koje pružaju osobe s invalidnosti, naučnici koji se bave invalidnošću i aktivisti u oblasti invaliditeta. Ovi izvori informacije su rutinski zanemareni u razgovorima pacijenata i davalaca medicinskih usluga, kao i u promotivnim aktivnostima koje sprovode proizvođači genetskih testova. ${ }^{18}$ Ovakvo isključivanje njihovog znanja o invalidnosti konstruiše osobe sa invaliditetom kao neadekvatne epistemičke izvore u procesu kreiranja znanja o genetičkom ispitivanju i invalidnosti. Putem takve selektivne razmene znanja, medicinsko osoblje i ustanove predstavljaju biomedicinsku nauku kao jedini pouzdan izvor znanja, a invalide kao nepouzdan. Shodno tome, rutinizacija i manjkav pristanak obaveštenog pacijenta stvaraju epistemički prostor $\mathrm{u}$

${ }^{18}$ Newell, C. (2006). Disability, bioethics, and rejected Knowledge. Journal of Medicine \& Philosophy, 31(3), str. 272. 
medicinskoj praksi u kojem se uzima zdravo za gotovo da su pacijenti i invalidi nesposobni za spoznaju, dok su medicinski radnici i ustanove nesporni epistemički autoriteti.

\section{DRUŠTVENA I ZAKONSKA DISKRIMINACIJA}

Rutinizacija i manjkavi pristanak obaveštenog pacijenta stvaraju uslove za diskriminatornu primenu biomedicinske nauke $\mathrm{u}$ društvenom kontekstu. Društvena i zakonska diskriminacija u ovom kontekstu se događaju na dva načina: kroz društvene i zakonske akte koji omalovažavaju invalidnost i kroz nepoštovanje postojeće društvene prakse i pravne zaštite koja podržava invalidnost kao oblik ljudske biološke i društvene raznolikosti. Istorijat primene društvenih i zakonskih akata za sprečavanje i uklanjanje invalidnosti kao oblika života u SAD obuhvata sledeće: a) institucionalizaciju invalida; b) prisilnu sterilizaciju invalida; i c) naučno eksperimentisanje na invalidima $u$ institucijama (npr. napuštenoj deci ili zatvorenicima). Iako većina ovih praksi više nije zakonski dozvoljena niti se primenjuje, savremena bioetika invalidnosti nastavlja da se bori sa ovom tradicijom i etičkim normama ukorenjenim u eugenici - diskriminatornoj primeni nauke genetike na društvenu sferu života. $^{19}$

Na primer, iako u SAD trenutno ne postoje savezni zakoni koji obavezuju građane da se podvrgnu genetičkom ispitivanju, većina pojedinačnih saveznih država zakonski nalaže rutinsko genetičko ispitivanje novorođenčadi. Iako u većini savenzih država ovi zakoni daju roditeljima mogućnost da odbiju ispitivanje, rutinski pregledi novorođenčadi obično se sprovode u ime zdravstvene zaštite. Stoga davaoci usluga rutinski zanemaruju da ekplicitno obaveste roditelje o njihovom pravu da odbiju genetsko ispitivanje, već smatraju da se pristanak roditelja podrazumeva. Neke savezne države propisuju zakonske kazne za davaoce usluga koji ne sprovedu ispitivanje, što

${ }^{19}$ Scully, J. (2008). Disability and genetics in the era of genomic medicine. Nature Reviews. Genetics, 9(10), str. 799. 
dodatno destimuliše diskusije o pristanku i neslaganju roditelja. Takvo pretenciozno genetičko ispitivanje na samom početku života daje roditeljima i javnosti do znanja da je podela ljudi na zdrave i nezdrave, sposobne i onesposobljene, one čiji su rezultati genetičkih analiza negativni i onih čiji su rezultati pozitivni, neophodna za održavanje društvenog poretka i stvar od velike važnosti za budućnost i dobrobit njihove dece kao i čitavog stanovništva.

Društvena diskriminacija u kontekstu rutinizacije se ne sprovodi samo zakonskim merama, već i kroz zagoravaranje genetičkog ispitivanja od strane epistemičkih autoriteta iz oblasti medicine i biomedicine. Iako ovakvi autoriteti nemaju zakonsku moć da regulišu upotrebu genetičkog ispitivanja, pretpostavlja se da su oni autoritativni izvori medicinskog znanja i njihove preporuke se bez zadrške prenose pacijentima i medicinskom osoblju. Na primer, Američki koledž akušera i ginekologa i Društvo za materno-fetalnu medicinu preporučuju rutinsko neinvazivno prenatalno testiranje svih trudnica, čak i kada klinička slika ne ukazuje na rizik od bolesti. Shodno tome, nakon komercijalizacije 2011. godine, neinvazivno genetičko ispitivanje se rutinski preporučuje trudnicama u SAD u svrhu otkrivanja predispozicije fetusa za hromozomske poremećaje, posebno one povezane sa aneuploidijom, genetskim mutacijama broja hromozoma. Jedan od najčešćih oblika aneuploidije je Trizomija 21 ili Daunov sindrom.

Rutinizacija ove neinvazivne medicinske mere omogućila je većem broju trudnica da saznaju da li postoji šansa da će roditi dete sa Daunovim sindromom. ${ }^{20}$ Posledice ovog povećanja teško je kvantitativno izmeriti. Studije kvantitativnih efekata rutinizacije neinvazivnog genetičkog ispitivanja koje se često fokusiraju na analiziranje uticaja neinvazivnog ispitivanja na odluke trudnica da prekinu trudnoću su dovele do značajno različitih rezultata i stoga se ne mogu

${ }^{20}$ Mollie A. Minear, M. A., Alessi, S., Allyse, M., Michie, M., and Chandrasekharan, S. (2015). Noninvasive Prenatal Genetic Testing: Current and Emerging Ethical, Legal, and Social Issues. Annu. Rev. Genomics Hum. Genet 16, str. 80 . 
generalizovati. ${ }^{21}$ Iako u tom smislu neusaglašena, ovakva kvantitativna istraživanja doprinose problemu rutinizacije jer stavljaju u prvi plan etičke dileme vezane za abortus, umesto pitanja o moralnoj obavezi da se prihvati raznovrsnost oblika ljudskog života. ${ }^{22}$ Drugim rečima, etička dilema u ovom kontekstu nije da li trudnici treba dozvoliti da abortira nakon dijagnoze Trizomije 21, već da li Daunov sindrom treba normalizovati kao dozvoljenu varijantu u genetskom sklopu ljudske rase. Ovakvo pogrešno formulisanje etičkog problema vezanog za neinvazivno genetičko ispitivanje implicitno podržava društvenu diskriminaciju prema invalidima jer zanemaruje želju i pravo invalida da žive.

Kvalitativno ispitivanje posledica rutinizacije genetičkih ispitivanja na ljudsko ponašanje i na ulogu koju ono ima u formiranju dominantnih kulturnih stavova i zajedničkih društvenih vrednosti pokazuje sledeće: a) rutinizacija genetičkih ispitivanja normalizuje stavove o invalidnosti kao tragediji koju treba izbeći po svaku cenu; b) selektivni abortus izražava negativne stavove ne samo o pojedinačnim oblicima invalidnosti, već i o ljudima koji ih poseduju; c) diskriminatorni stavovi prema prediktivnoj invalidnosti mogu negativno uticati na stavove roditelja prema sopstvenoj deci sa invaliditetom; i d) komercijalizacija genetičkog ispitivanja zagovara stav da troškove zdravstvene zaštite za osobe sa invaliditetom treba razmatrati u odnosu na troškove proizvodnje i sprovođenja genetičkog testa koji se koristi da bi se odlučilo da li čovek sa invaliditetom treba da bude začet ili uopšte rođen. $^{23}$

Ovi problemi mogli bi se delimično rešiti podržavanjem zakona o genetičkom ispitivanju. U SAD, Zakon o obaveštavanju o prenatalno i postnatalno dijagnostikovanim stanjima (Prenatally and Postnatally

${ }^{21}$ Norwitz, E. R., Phaneuf E. L., i Levy, B. (2016) Noninvasive prenatal testing: The future is now. Review in Obstetrics and Gynecology 6(2), str. 48.

${ }^{22}$ Ravitsky, V. (2017) The shifting landscape of prenatal testing: Between reproductive autonomy and public health," Just Reproduction: Reimagining Autonomy in Reproductive Medicine, special report, Hastings Center Report 47 (6), str. 37.

${ }^{23}$ Parens, E., \& Asch, A. (1999). The Disability Rights Critique of Prenatal Genetic Testing: Reflections and Recommendations. The Hastings Center Report, 29(5), str. 16. 
Diagnosed Conditions Awareness Act) najznačajniji je akt saveznog zakona koji se bavi pravima u genetičkom ispitivanju. ${ }^{24}$ Ovaj zakon ima sledeće ciljeve: a) da trudnicama koje su suočene sa dijagnozom Daunovog sindroma ili drugih invalidnosti daju informaciju o uslugama za osobe sa tim invalidnostima, kao i tačne informacije o kvalitetu života pojedinaca koji žive s tim invalidnostima; b) jačanje saradnje među vladinim agencijama, pacijentima i programima pružalaca usluga; i c) da osigura da pacijenti dobiju informacije zasnovane na dokazima o svrsishodnosti i tačnosti rezultata genetičkih testova. Uprkos važnosti ovog zakona, od svog donošenja 2008. godine, američka vlada nije obezbedila finansijska sredstva koja bi bila dovoljna za njegovo dosledno sprovođenje. Mnoge savezne države su usvojile zakone slične ovom saveznom zakonu, ali njihova formulacija ciljeva i propisanih procedura varira u velikoj meri, dok je njihov doprinos borbi protiv diskriminacije invalida nejasan.

Bioetičari invalidnosti se, međutim, slažu da je čak i u potpunom odsustvu zakonskih direktiva etički neophodno dostavljati činjenične i sveobuhvatne informacije o svrsishodnosti testova i tačnosti rezultata ispitivanja kao i o kvalitetu života osoba sa invalidnosti. Trenutno nijedno od ovih razmatranja nije deo rutinskih razgovora između davalaca medicinskih usluga i pacijenata ni pre ni posle genetičkog ispitivanja. Naučna istraživanja u oblasti studija invalidnosti kao i primeri iz iskustva osoba sa invalidnostima pokazuju kako medinsko osoblje često daje pacijentima obaveštenja koja preuveličavaju tačnost rezultata testova i potcenjuju kvalitet života invalida. ${ }^{25}$

Konačno, reklame i promotivni materijali o genetičkom ispitivanju ne pominju da su osobe sa invalidnosti zaštićene antidiskriminacionim zakonima. Lekari takođe rutinski ne obaveštavaju pacijente o zakonima kojima se invalidi štite od diskriminacije. U SAD

${ }^{24}$ Prenatally and Postnatally Diagnosed Conditions Awareness Act, Pub. L. No.110-374, § 2(1)-(3), 122 Stat. 4051, 4051 (2008).

${ }^{25}$ Parens, E., \& Asch, A. (1999). The Disability Rights Critique of Prenatal Genetic Testing: Reflections and Recommendations. The Hastings Center Report, 29(5), str. 21; Suter, S. (2002). Routinization of Prenatal Testing. American Journal of Law and Medicine 28, str. 240. 
Zakon o rehabilitaciji (Rehabilitation Act) i Zakon o Amerikancima sa invalidnosti (Americans with Disabilities Act) su dve centralne zakonske mere kojima se reguliše diskriminacija prema invalidima. Iako ni jedan od ovih zakona trenutno ne štiti nerođene osobe sa invalidnosti tako da nosioci i roditelji ne mogu biti odgovorni pred zakonom za diskriminaciju sopstvene nerođene dece zbog invalidnosti, nije opravdano da se informacije o ovim zakonima izuzmu kao način da se nosiocima i potencijalnim roditeljima pokaže da bi njihova deca bila priznata kao zakoniti članovi društva. Zakone koji štite invalidnost kao oblik ljudske biološke i socijalne raznolikosti treba, dakle, uključiti u obaveštenja koja lekari daju pacijentima, kao i u preporuke koje izdaju naučni autoriteti u oblasti medicine, kao što su gore navedeni Američki koledž akušera i ginekologa i Društvo za materno-fetalnu medicinu. Iako nijedna od ovih profesionalnih organizacija, kao ni zakoni o zabrani diskriminacije zakonski ne rukovode odluke pacijenata $u$ vezi sa genetičkim ispitivanjem, oni oblikuju način na koji pacijenti i javnost razmišljaju o pojmu invalidnosti i o invalidima.

U zaključku, bioetika invalidnosti problematizuje rutinizaciju medicinskih mera i pojam pristanka obaveštenog pacijenta tako da ističe emotivnu povredu, epistemičku nepravdu i društvenu i pravnu diskriminaciju u kontekstu genetičkog ispitivanja. Bioetičari invalidnosti tvrde da rutinizacija genetičkih ispitivanja propagira negativne stavove prema invalidnosti kao obliku ljudske različitosti i da pristanak obaveštenog pacijenta ne ispunjava zakonske mere kojima se invalidnost potvrđuje kao varijacija biodiverziteta.

Stoga bioetičari koji se bave invalidnošću često preporučuju sledeće promene u medicinskoj praksi: a) lekari ne treba rutinski da preporučuju genetičko ispitivanje kao sredstvo za označavanje invaliditeta kao tragedije, niti da ga preporučuju i reklamiraju kao deo primarne medicinske prakse; b) pacijentima treba pružiti sveobuhvatne informacije o tačnosti rezultata genetskih testova i kvalitetu života osoba sa invaliditetom; i c) medicinsko osoblje pri svakodnevnoj upotrebi biomedicinskih istraživanja u razgovoru sa pacijentima, treba da temelji obaveštenja o svrsi genetičkog ispitivanja pre svega na nemedicinskim informacijama koje pružaju osobe sa invalidnosti ili naučna istraživanja 
koja ukazuju na suštinsku vrednost životnog iskustva invalidnosti. Na kraju krajeva, sa stanovišta bioetike invalidnosti, invalidnost je ispoljenje biološke i društvene raznolikosti ljudske rase i ne može se svesti na utvrđivanje biomedicinske anomalije.

\section{LITERATURA}

Agarwal, A., Sayres, L. C., Cho, M. K., Cook-Deegan, R., \& Chandrasekharan, S. (2013). Commercial landscape of noninvasive prenatal testing in the United States. Prenatal diagnosis, 33 (6), 521-531.

Amundson, T. (2008). Bioethics and disability rights: Conflicting values and perspectives. Journal of Bioethical Inquiry, 5(2), 111-123.

Andrews, L. B. (1996). Prenatal screening and the culture of motherhood. Hastings L.J., 47, 967 - 998.

Asch, A. (2001). Disability, bioethics and human rights in Albrecht, G., Seelman, K., \& Bury, M. (eds.) (2001). Handbook of disability studies. Sage Publications, 297-327.

Farrell, R., Agatisa, P., Mercer, M., Mitchum, A., \& Coleridge, M. (2016). Expanded indications for noninvasive prenatal genetic testing: Implications for the individual and the public. Ethics, Medicine, and Public Health, 2(3), 383-391.

Hall, D. E., Prochazka, A. V., \& Fink, A. S. (2012). Informed consent for clinical treatment. CMAJ: Canadian Medical Association journal $=$ Journal de l'Association medicale canadienne, 184(5), 533-540.

Longmore, P. K., (1995). Medical decision making and people with disabilities: A clash of cultures. Journal of Law and Medical \& Ethics 23 (1), 82-87.

Mollie A. Minear, M.A., Alessi, S., Allyse, M., Michie, M., and Chandrasekharan, S. (2015). Noninvasive Prenatal Genetic Testing: Current and Emerging Ethical, Legal, and Social Issues. Annual Review in Genomics and Human Genetics 16, 369-98.

Murray, B. (2012). Informed consent: what must a physician disclose to a patient. Virtual Mentor. 2012; 14(7):563-566. doi: 10.1001/virtualmentor.2012.14.7.hlaw1-1207. https://journalofethics.ama-assn.org/article/informed-consent-whatmust-physician-disclose-patient/2012-07

National Council on Disability (2019). Genetic testing and the rush to perfection (Bioethics and Disability Series). U.S. National Council on Disability. 
Newell, C. (2006). Disability, bioethics, and rejected knowledge. Journal of Medicine \& Philosophy, 31(3), 269-283.

Norwitz, E. R., Phaneuf E. L., i Levy, B. (2016) Noninvasive prenatal testing: The future is now. Review in Obstetrics and Gynecology 6(2): 48-62.

Ouellette, A. (2011). Bioethics and disability: Toward a disability-conscious bioethics (Cambridge Disability Law and Policy Series). Cambridge: Cambridge University Press.

Parens, E. and Asch, A. (2003). Disability rights critique of prenatal genetic testing: Reflections and recommendations. Ment. Retard. Dev. Disabil. Res. Rev., 9: 40-47

Parens, E., \& Asch, A. (1999). The disability rights critique of prenatal genetic testing: Reflections and recommendations. The Hastings Center Report, 29(5), 1-24.

Prenatally and Postnatally Diagnosed Conditions Awareness Act, Pub. L. No.110-374, § 2(1)-(3), 122 Stat. 4051, 4051 (2008)

Ravitsky, V. (2017). The shifting landscape of prenatal testing: Between reproductive autonomy and public health. Just Reproduction: Reimagining Autonomy in Reproductive Medicine, special report, Hastings Center Report 47, no. 6 (2017): S34-S40.

Suter, S. (2002). Routinization of Prenatal Testing. American Journal of Law and Medicine 28, 233-270.

Scully, J. (2008). Disability and genetics in the era of genomic medicine. Nature Reviews. Genetics, 9(10), 797-802.

Scully, J. (2008). Disability bioethics: Moral bodies, moral difference. Lantham: Rowman\&Littlefield Publishers, Inc.

ANDJELA H. KAUR

University of North Dakota, Grand Forks, North Dakota, USA

\title{
RUTINIZATION OF GENETIC TESTING AND DISABILITY, A BIOETHICAL ANALYSIS
}

\begin{abstract}
Technological advancements in biomedicine introduce new ethical questions in the practice of medicine. The invention of non-invasive genetic testing is one example that calls for problematization of the achievements in
\end{abstract}


biomedical science. Since the commercialization of non-invasive genetic testing in the United States and globally, genetic testing has been increasingly popularized as a necessary part of routine health care. This paper argues that the routinization of genetic testing increases disability discrimination in the professional practice of medicine and normalizes disability prejudice in the society.

Keywords: Disability bioethics, Genetic testing, Rutinization of medical interventions, Inform consent, Emotional harm, Epistemic injustice, Social and legal discrimination

Primljeno: 31.8 .2020 . Prihvaćeno: 11.11.2020. 